\title{
First report of pulmonary sclerosing pneomucytoma with malignant transformation in both cuboidal surface cells and stromal round cells: a case report
}

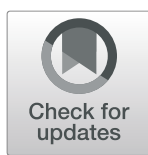

Xiao Teng ${ }^{1}$ and Xiaodong Teng ${ }^{2^{*}}$ (1)

\begin{abstract}
Background: Pulmonary sclerosing pneumocytoma (PSP) is a rare benign tumor. Although lymph node metastasis has been reported, it is still considered benign. No malignant transformation has been reported. This is the first case of malignant transformation of both cuboidal surface cells and stromal round cells.

Case presentation: A 64-year-old male had been complaining of intermittent hemoptysis several times per day for eight months. Chest computed tomography scan showed parenchymal infiltration with cystic lesion in the right lower lobe accompanied by enlarged right hilar lymph nodes. Lobectomy and systemic lymph node dissection was performed.

On grossly pathological examination, the lesion was $50 \mathrm{~mm}$ from the bronchial stump. It was a mixture of both cystic and solid components and $30 \mathrm{~mm} * 20 \mathrm{~mm}$ in size with unclear border. Microscopically, the cuboidal surface cells transformed to adenocarcinoma. The stromal round cells also had a malignant transformation. The Ki-67 proliferation index in malignant cuboidal surface cells and stromal round cells were 70 and 55\%, respectively. Furthermore, E-cadherin was negative in primary tumor but positive in metastatic lymph node, which suggested that the mesenchymal to epithelial transition may play an important role in lymph node metastasis.

Conclusions: To our knowledge, we present the first case of malignant transformation of both cuboidal surface cells and stromal round cells in PSP. The process of mesenchymal to epithelial transition may play an important role in lymph node metastasis.
\end{abstract}

Keywords: Pulmonary sclerosing pneomucytoma, Malignant transformation, Mesenchymal to epithelial transition, Stromal round cell, Cuboidal surface cell

\section{Background}

Pulmonary sclerosing pneumocytoma (PSP) is a rare benign tumor which has been described as sclerosing hemangioma [1]. It was previously considered as a vascular neoplasm, and now as a derivative from the primitive respiratory epithelium [2]. It is predominant in females, most commonly seen in middle aged females [3, 4]. Patients are always asymptomatic and computed tomography $(\mathrm{CT})$ and X-ray of chest shows

\footnotetext{
* Correspondence: teng1102069@zju.edu.cn

${ }^{2}$ Department of Pathology, The First Affiliated Hospital, School of Medicine,

Zhejiang University, Hangzhou, Zhejiang, China

Full list of author information is available at the end of the article
}

solitary, well circumscribed masses. The key pathological features of PSP involve two types of cells, cuboidal surface cells and stromal round cells, which are both neoplastic. Immunohistochemistry (IHC) studies show that thyroid transcription factor-1 (TTF1) and epithelial membrane antigen (EMA) are both positive [2]. Pancytokeratin (CKpan) and Napsin A are both positive in cuboidal surface cells, while negative in stromal round cells [5]. Though lymph node metastasis has been reported, PSP is still considered benign [6,7]. We report a unique case of PSP with malignant transformation in both cuboidal surface

(c) The Author(s). 2019 Open Access This article is distributed under the terms of the Creative Commons Attribution 4.0 International License (http://creativecommons.org/licenses/by/4.0/), which permits unrestricted use, distribution, and 
cells and stromal round cells, which has not been reported before.

\section{Case presentation}

A 64-year-old male had been complaining of intermittent hemoptysis several times per day for eight months. He had no fever, chest pain, shortness of breath, dizziness or amaurosis. He had no relevant medical history especially no history of cancer. He had no smoking history. The patient was admitted to The First Affiliated Hospital, School of Medicine, Zhejiang University due to symptoms getting worse. Chest computed tomography scan on July 1st, 2018 showed parenchymal infiltration with cystic lesion in the right lower lobe accompanied by enlarged right hilar lymph nodes (Fig. 1). Transbronchial lung biopsy under bronchofibroscopy was free of tumor cells. A primary surgical resection was recommended by surgeons. Lobectomy and systemic lymph node dissection was done on July 4th, 2018. The patient is now well after he recovered from surgery. So far there were no signs of tumor recurrence or metastasis.

Upon grossly pathological examination, the lesion was located in the right lower lobe, $50 \mathrm{~mm}$ from the bronchial stump. It was gray-tan to yellow on the section, with foci of hemorrhage. The lesion was a mixture of both cystic and solid components and was 30 $\mathrm{mm} * 20 \mathrm{~mm}$ in size with unclear border. The solid component was in the middle of the lesion and was $17 \mathrm{~mm} * 17 \mathrm{~mm}$ in size, surrounded by honeycomb cystic components.

Microscopically, the structure of the solid component of the tumor was similar to a typical PSP. It was composed of areas of cuboidal surface cells and stromal round cells. The tumor showed a hemorrhage pattern (Fig. 2). Bronchial adenomatous hyperplasia and cystic dilatation were noticed in surrounding areas. TTF-1 and EMA were positive in both cuboidal surface cells and stromal round cells (Fig. 2) while CKpan and Napsin A were only positive in cuboidal surface cells.

In the case reported, while most of the surface cells being similar to a typical PSP in some areas of the tumor, a few transformed to adenocarcinoma. The nuclei were columnar and containing hyperchromatic nuclear chromatin. In addition, the surface cells replaced the alveolar lining and invaded the fibrous stroma and vascular walls with TTF-1, EMA, Napsin A and CKpan all positive. The Ki-67 proliferation index was $70 \%$ (Fig. 3). We also noticed atypical adenomatous hyperplasia (AAH) of cuboidal cells in the transition area (Fig. 3). Cuboidal surface cells proliferated along preexisting alveolar walls with mild to moderate cellular atypia. A typical hobnail appearance was also seen in the atypical cuboidal surface cells. Substantial gaps along the surface of basement membrane in the transition area were also evident of AAH.

A few stromal round cells had small, well-defined borders and central bland nuclei without nucleoli similar to that in a typical PSP. However, mild to moderate atypical stromal round cells proliferation was seen in the transition region (Fig. 4). Binuclearization and intranuclear eosinophilic inclusions were common in the transition area in our case. Furthermore, abundant cytoplasm, nuclear polymorphism, prominent nucleoli and irregular mitosis were observed in malignant stromal round cells, adjoining the transition areas (Fig. 4). Vascular invasion

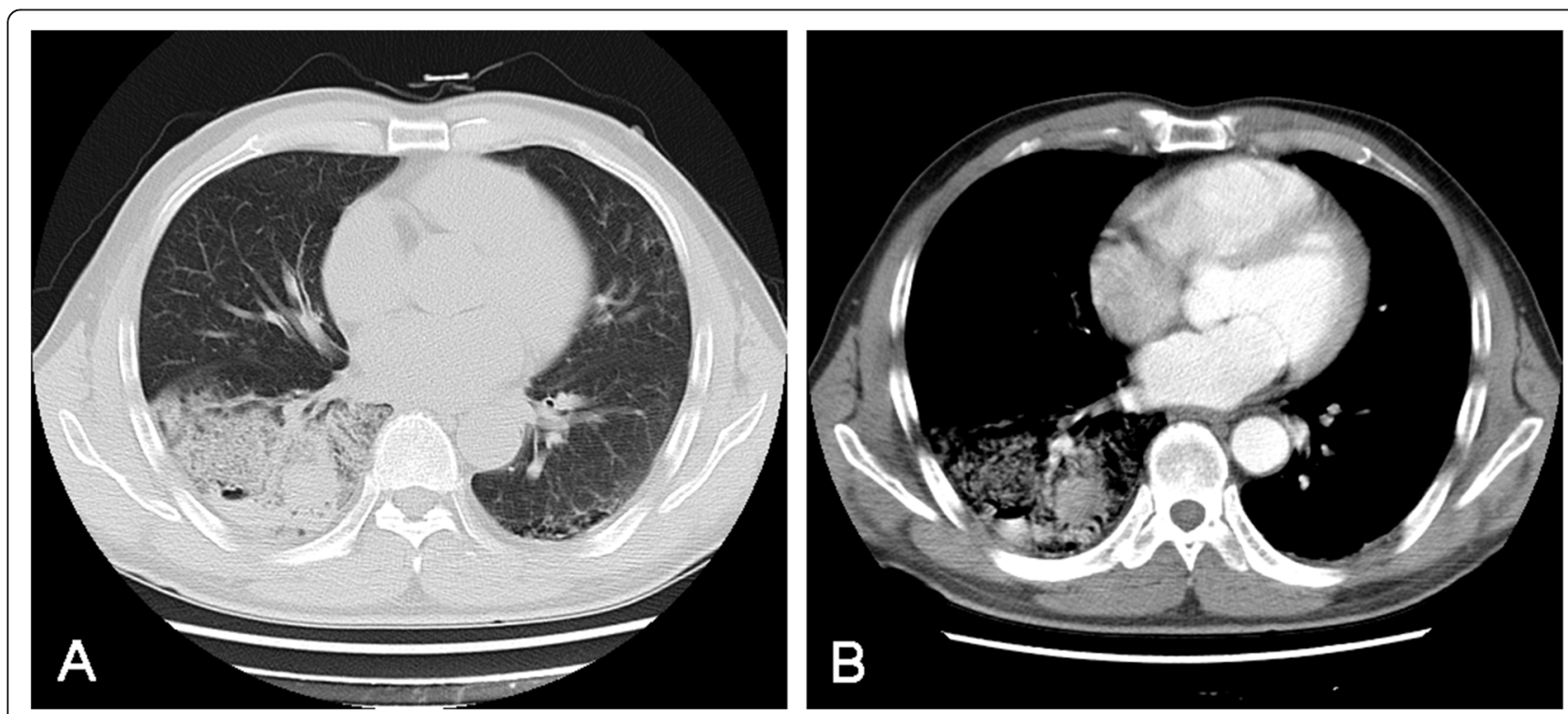

Fig. 1 Chest computed tomography scan showed that parenchymal infiltrate with cystic lesion in the right lower lobe of lung 

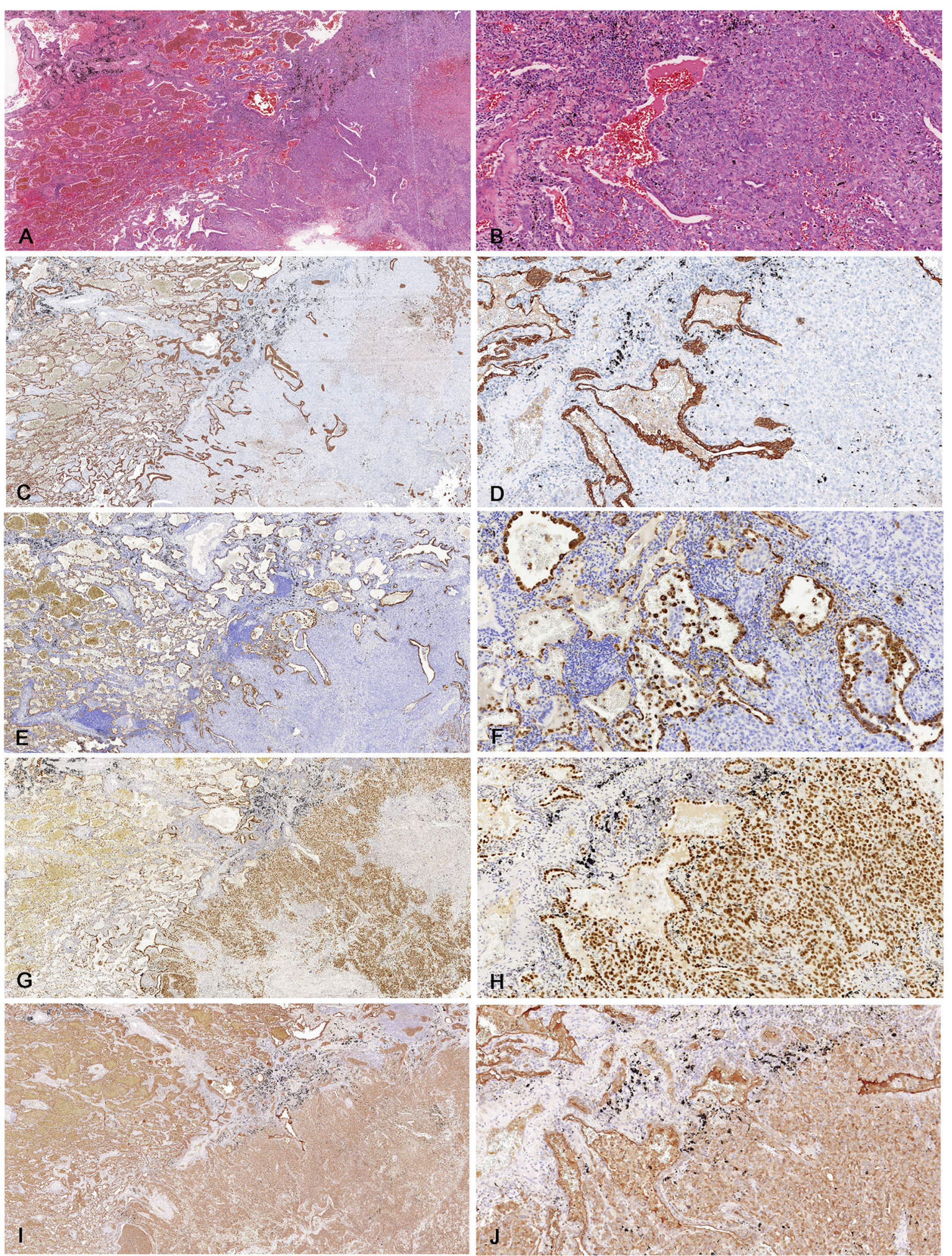

Fig. 2 (a, b) Tumor nodule showed a typical pulmonary sclerosing pneumocytoma of hemorrhage growth pattern comprising of large blood-filled spaces lined by surface cells $(\mathbf{h} \& \mathbf{e})$. (c, d) Cuboidal surface cell were positive for pancytokeratin (CKpan), round cells were negative for CKpan. (e, $\mathbf{f}$ ) Cuboidal surface cell were positive for Napsin A, round cells were negative. $(\mathbf{g}, \mathbf{h})$ Both cuboidal surface and stromal round cells were positive for thyroid transcription factor-1 (TTF-1). (i, j) Both cuboidal surface and stromal round cells were positive for epithelial membrane antigen (EMA) 


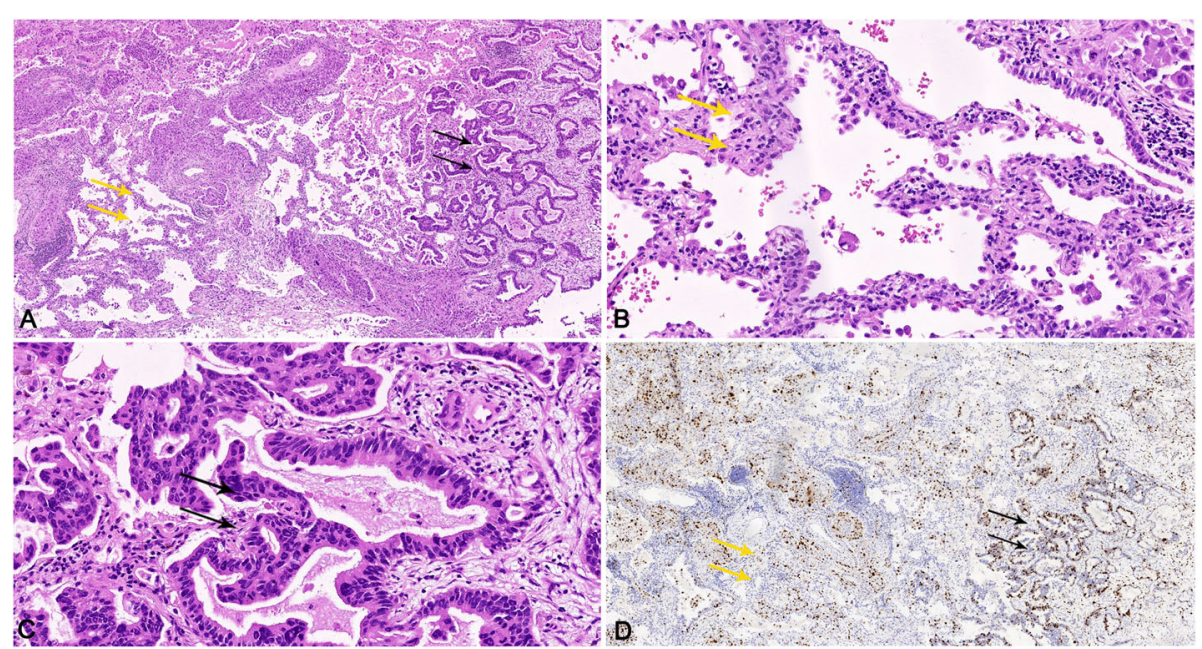

Fig. 3 (a, b, c) Tumor nodule showed surface cells (yellow arrow) with atypical adenomatous hyperplasia transformed into adenocarcinoma (black arrow) (h\&e). (d) Ki-67 proliferation index was significantly increased in malignant area (black area)

and pulmonary parenchyma involvements were also found in malignant lamellarlike stromal round cells. TTF-1, P63 and EMA were all positive. Only a small amount stromal round cells were positive for CKpan. However, stromal round cells were negative for betacatenin and E-cadherin. The Ki-67 proliferation index in these areas was $55 \%$, which was significantly increased compared to typical PSP areas (Fig. 4). Both stromal round cells and surface cells were negative for Progesterone receptor, CD20, CD3, $\mathrm{S}^{-100}$, Melana, HMB45, Myogenin, MyoD1, CgA and Syn. Further molecular investigation using a polymerase chain reaction panel showed that no EGFR, ALK or ROS1 mutation was detected.

In this case, we also found mediastinal lymph nodes involvement. The architecture of lymph nodes was replaced

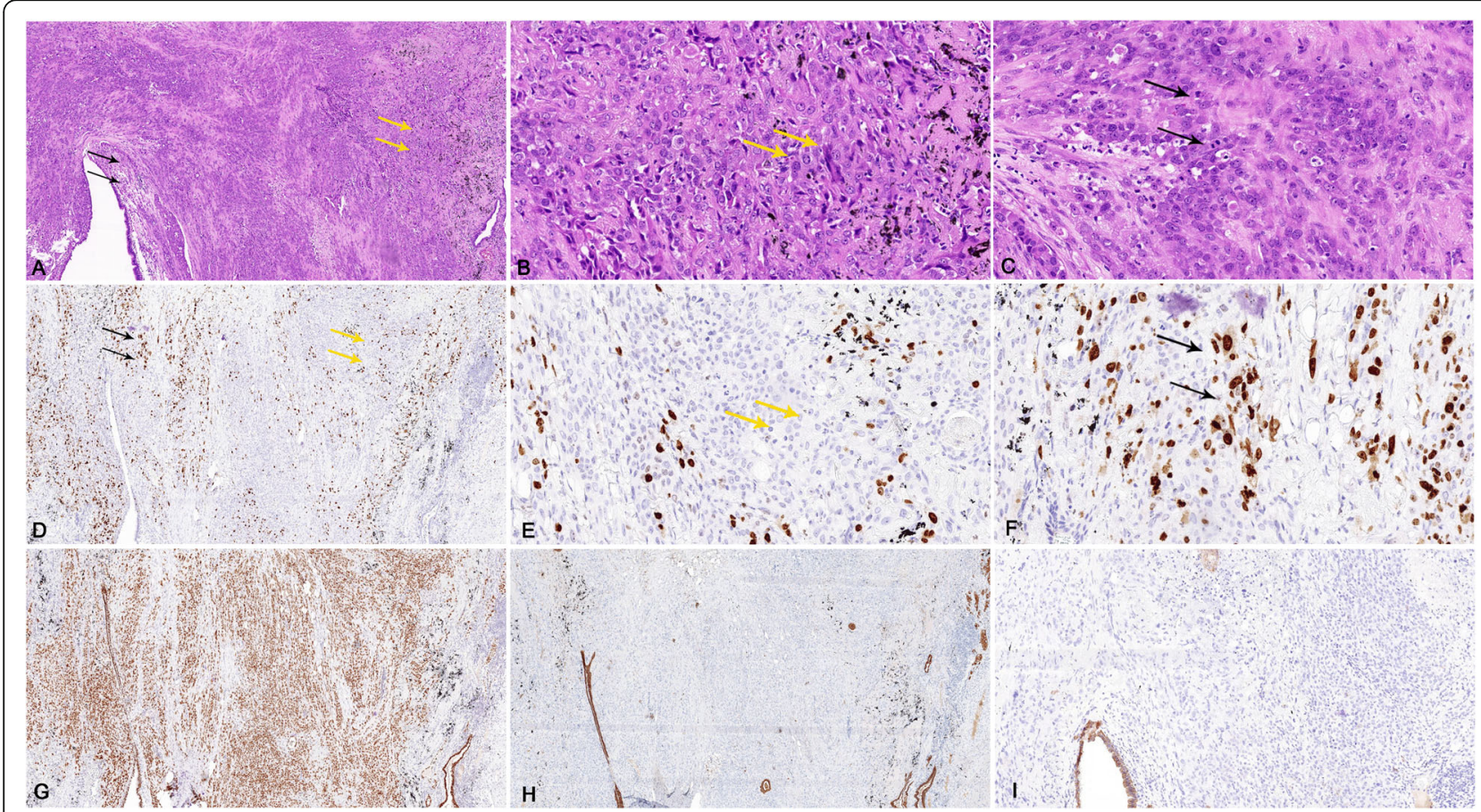

Fig. $4(\mathbf{a}, \mathbf{b}, \mathbf{c})$ Low power view and high power view demonstrated that stromal round cells in the left side transformed to the malignant tumor (black arrow), round cells in the transition area (yellow arrow) had dysplasia $(\mathbf{h} \& \mathbf{e}) .(\mathbf{d}, \mathbf{b}, \mathbf{f})$ Low power view and high power view demonstrated that Ki-67 proliferation index was significantly increased in the malignant area (black arrow). (g) Thyroid transcription factor-1 (TTF-1) was positive in stromal round cells. (h) Pancytokeratin was negative in stromal round cells. (i) E-cadherin was negative in stromal round cells 


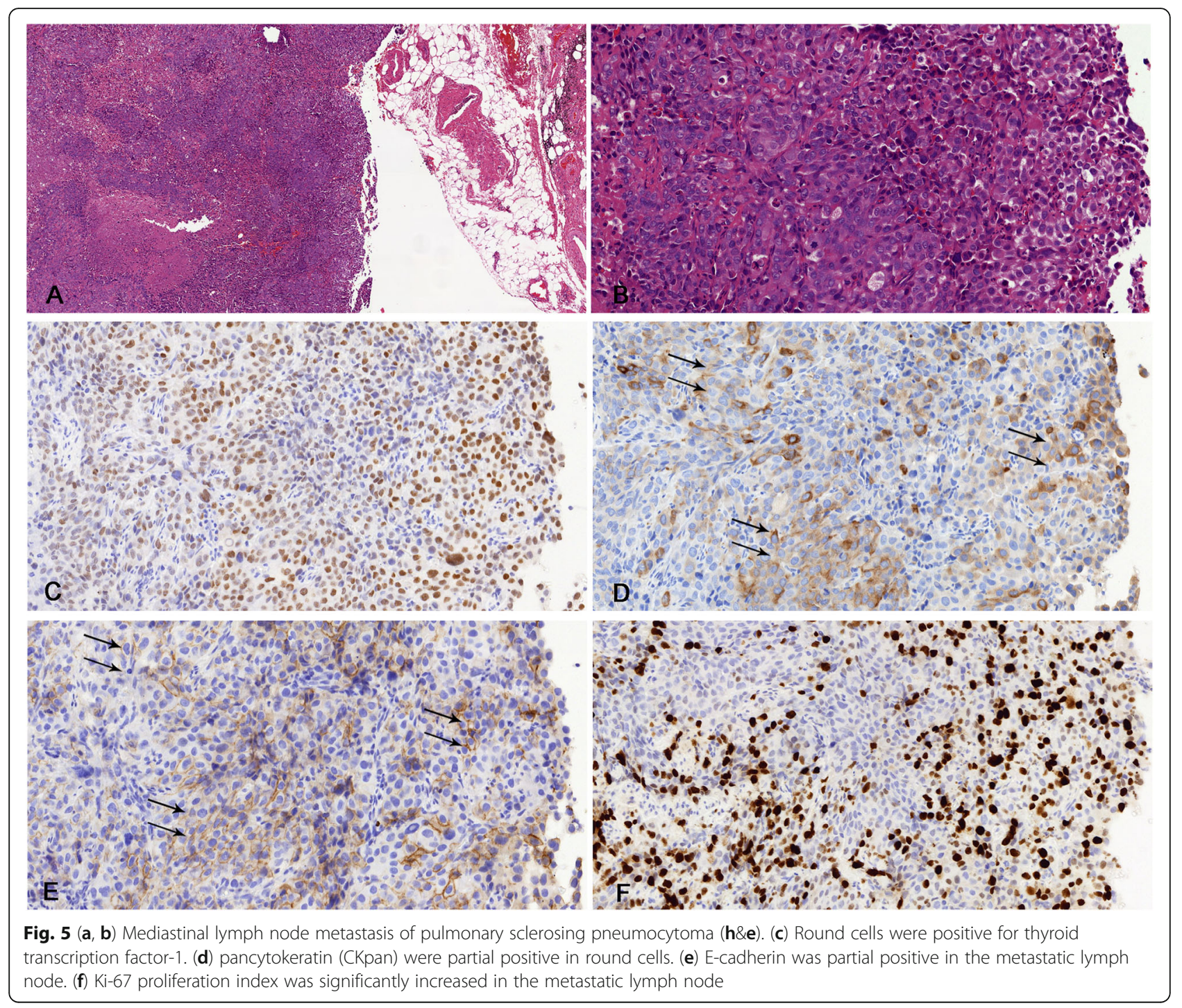

by abnormal proliferated stromal round cells with either vacuolated or eosinophilic cytoplasm (Fig. 5). IHC showed that these cells were positive for TTF-1, partial positive for CKpan and E-cadherin, but negative for beta-catenin. However, the E-cadherin was negative in malignant stromal round cells in the primary tumor (Fig. 4).

\section{Discussion and conclusion}

PSP is considered as a rare benign tumor [1]. In searches of PubMed and Embase database, there are 24 cases of PSP with lymph node metastasis and recurrence (Table 1) [2, 6-25]. Five cases have mediastinal lymph node metastasis, four have distant metastasis, and only one have recurrence of PSP. However, no case about malignant transformation of PSP has been reported. One case reports overgrown stromal round cells and bone metastasis, accompanied by increased cellularity and necrotic areas, but a Ki67 index of less than 5\% [22]. Another case reports PSP with metastatic spread to stomach with Ki-67 indeice in primary tumor and metastatic gastric lesion of 17.6 and $19.4 \%$, respectively [19]. The. However, no malignant pathomorphological change has been reported. In Iyoda's research, cases with recurrence has a Ki-67 index of $0.4 \%$ [26]. These results show no significantly increased proliferation of cells even in patients with recurrence or metastasis. In our case, the $\mathrm{Ki}-67$ proliferation index of the malignant $\mathrm{cu}$ boidal surface cells and the stromal round cells are 70 and 55\%, respectively. The high proliferative activity and pathomorphological change in both cuboidal surface cells and stromal round cells suggest that PSP transformed to a malignant tumor. Liu reports a case of coexistence of PSP and primary adenocarcinoma in the same tumor [27], which is different from our 
Table 1 Studies of PSP with metastasis or recurrence

\begin{tabular}{|c|c|c|c|c|c|}
\hline Author (Year) & Age & Gender & Primary location & Tumor size $(\mathrm{mm})$ & Recurrence/ Metastatic site \\
\hline Tanaka I (1986) [8] & 22 & Male & Right lower lobe & 50 & Hilar lymph node \\
\hline Chan AC (2000) [9] & 48 & Male & Right lower lobe & 80 & Hilar lymph node \\
\hline Devouassoux-Shisheboran M (2000) [2] & 18 & Female & Left lower lobe & 35 & Hilar lymph node \\
\hline Yano M (2002) [10] & 67 & Female & Right lower lobe & 90 & Hilar lymph node \\
\hline Kim KH (2003) [11] & 19 & Female & Left lower lobe & 100 & Hilum and intralobular lymph node \\
\hline Kim GY (2003) [12] & 37 & Female & Left lower lobe & 20 & Supraclavicular lymph node \\
\hline \multirow[t]{4}{*}{ Miyagawa-Hayashino A (2003) [13] } & 10 & Female & Right middle lobe & 47 & Regional lymph node \\
\hline & 45 & Female & Right upper lobe & 25 & Hilar lymph node \\
\hline & 45 & Male & Left lower lobe & 37 & Mediastinal lymph node \\
\hline & 50 & Female & Left lower lobe & 15 & Intralobular lymph node \\
\hline Chan NG (2003) [14] & 19 & Male & Left upper lobe & 30 & Intralobular lymph node \\
\hline Katakura H (2005) [15] & 35 & Male & Left lower lobe & - & Mediastinal lymph node \\
\hline Jiang ZN (2007) [16] & 59 & Female & Right lower lobe & 65 & Hilar lymph node \\
\hline Wei S (2008) [9] & 57 & Female & Left lower lobe & 25 & Recurrence \\
\hline Vaideeswar P (2009) [17] & 23 & Male & Right upper lobe & 90 & Hilar lymph node \\
\hline Suzuki H (2011) [18] & 57 & Female & Right lower lobe & 25 & Pleural dissemination \\
\hline Bae YS (2012) [19] & 72 & Female & Left lobe & 32 & Stomach \\
\hline Kita H (2013) [20] & 38 & Female & Left lower lobe & 39 & Interlober lymph node \\
\hline Adachi Y (2014) [6] & 40 & Female & Left lower lobe & 10 & Mediastinal lymph node \\
\hline Xu HM (2015) [21] & 26 & Female & Right upper lobe & 97 & Hilar lymph node \\
\hline Kim MK (2015) [22] & 73 & Female & Right lower lobe & 35 & Bone \\
\hline Pokharel S (2016) [7] & 33 & Female & Left lower lobe & 18 & Mediastinal lymph node \\
\hline Soo IX (2017) [23] & 40 & Female & Right lower lobe & 25 & Mediastinal lymph node \\
\hline Wang X (2018) [24] & 26 & Female & Left lower lobe & 40 & Mediastinal and regional lymph nodes \\
\hline
\end{tabular}

case, where the AAH of cuboidal surface cells indicated malignant transformation from cuboidal surface cells to adenocarcinoma. Similarly, the malignant transformation of stromal round cells is also confirmed by the transition region.

In our case, the two well-established epithelial markers, E-cadherin and CKpan [28], are both positive in the metastatic lymph nodes with similar levels (black arrows in Fig. 5), although they should be negative in metastatic lymph nodes (composed of stromal round cells). The epithelial marker expression in metastatic lymph nodes suggests the mesenchymal-epithelial transition (MET) during lymph node metastasis. Previous studies show that MET process is able to promote distal metastasis in breast cancer [29], especially for establishing macrometastasis [30-32], which, combined with our results, suggests that the the MET process may play an important role in lymph node metastasis of PSP. Although based on previous studies, lymph node involvement doesn't affect long-term survival rate $[6,23]$, patients with malignant PSP may still need close follow-up.

In summary, we report the first case of malignant transformation in both cuboidal surface cells and stromal round cells, which suggests the malignant potential of PSP. The fact that E-cadherin is negative in primary tumor but positive in metastatic lymph nodes suggests that the process of MET plays an important role in lymph node metastasis of PSP.

\section{Abbreviations \\ AAH: Typical adenomatous hyperplasia; CKpan: Pancytokeratin; CT: Computed tomography; EMA: Epithelial membrane antigen; IHC: Immunohistochemistry; MET: Mesenchymal-epithelial transition; PSP: Pulmonary sclerosing pneumocytoma; TTF-1: Thyroid transcription factor-1}

\section{Acknowledgements}

The authors express gratitude to all the technical and clinical staffs involved in patient management and laboratory diagnosis.

\section{Sources of funding}

This research did not receive any specific grant from funding agencies in the public, commercial, or nonprofit sectors.

\section{Authors' contributions}

TX collected the data, reviewed the literature, drafted and edited the manuscript. TXD conceived the study, participated in experiment design and data acquisition and edited the manuscript. All authors read and approved the final manuscript. 


\section{Availability of data and materials}

The datasets used in this study are available from the corresponding author on reasonable requests.

\section{Ethics approval and consent to participate}

The study received ethics approval from the Commission for Scientific Research in the First Affiliated Hospital, School of Medicine, Zhejiang University. The patient provided written informed consent.

\section{Consent for publication}

Written informed consent was obtained from the patient and his healthy sibling for the publication.

\section{Competing interests}

The authors declare that they have no competing interests.

\section{Author details}

'Department of Thoracic Surgery, The First Affiliated Hospital, School of Medicine, Zhejiang University, Qingchun Road 79, Hangzhou, Zhejiang 310003, People's Republic of China. ${ }^{2}$ Department of Pathology, The First Affiliated Hospital, School of Medicine, Zhejiang University, Hangzhou, Zhejiang, China.

Received: 15 April 2019 Accepted: 11 November 2019

Published online: 27 November 2019

\section{References}

1. Travis WD, Brambilla E, Nicholson AG, et al. The 2015 World Health Organization classification of lung tumors: impact of genetic, clinical and radiologic advances since the 2004 classification. J Thorac Oncol. 2015;10:1243-60.

2. Devouassoux-Shisheboran M, Hayashi T, Linnoila Rl, et al. A clinicopathologic study of 100 cases of pulmonary sclerosing hemangioma with immunohistochemical studies: TTF-1 is expressed in both round and surface cells, suggesting an origin from primitive respiratory epithelium. Am J Surg Pathol. 2000;24:906-16.

3. Zhu J. Analysis of the clinical differentiation of pulmonary sclerosing pneumocytoma and lung cancer. J Thorac Dis. 2017;9:2974-81.

4. Yang $\mathrm{CH}$, Lee $\mathrm{LY}$. Pulmonary sclerosing pneumocytoma remains a diagnostic challenge using frozen sections: a clinicopathological analysis of 59 cases. Histopathology. 2018;72:500-8.

5. Zhou J, Covinsky MH. Sclerosing Pneumocytoma: a carcinoma mimicker. A case report and literature review. Ann Clin Lab Sci. 2017;47:103-5.

6. Adachi Y, Tsuta K, Hirano R, et al. Pulmonary sclerosing hemangioma with lymph node metastasis: a case report and literature review. Oncol Lett. 2014:7:997-1000

7. Pokharel S, Dhillon SS, Ylagan L, et al. Sclerosing Pneumocytoma with lymph node metastasis. J Thorac Oncol. 2016:11:1802-4.

8. Tanaka I, Inoue M, Matsui Y, et al. A case of pneumocytoma (so-called sclerosing hemangioma) with lymph node metastasis. Jpn J Clin Oncol. 1986;16:77-86.

9. Chan AC, Chan JK. Pulmonary sclerosing hemangioma consistently expresses thyroid transcription factor-1 (TTF-1): a new clue to its histogenesis. Am J Surg Pathol. 2000;24:1531-6.

10. Yano M, Yamakawa Y, Kiriyama M, et al. Sclerosing hemangioma with metastases to multiple nodal stations. Ann Thorac Surg. 2002;73:981-3.

11. Kim KH, Sul HJ, Kang DY. Sclerosing hemangioma with lymph node metastasis. Yonsei Med J. 2003;44:150-4.

12. Kim GY, Kim J, Choi YS, et al. Sixteen cases of sclerosing hemangioma of the lung including unusual presentations. J Korean Med Sci. 2004;19:352-8.

13. Miyagawa-Hayashino A, Tazelaar HD, Langel DJ, Colby TV. Pulmonary sclerosing hemangioma with lymph node metastases: report of 4 cases. Arch Pathol Lab Med. 2003;127:321-5.

14. Chan NG, Melega DE, Inculet Rl, Shepherd JG. Pulmonary sclerosing hemangioma with lymph node metastases. Can Respir J. 2003;10:391-2.

15. Katakura H, Sato M, Tanaka F, et al. Pulmonary sclerosing hemangioma with metastasis to the mediastinal lymph node. Ann Thorac Surg. 2005;80:2351-3.

16. Jiang ZN, Zhu T, Jin M, Wang LB. Sclerosing hemangioma with lymph node metastasis: report of a case. Zhonghua Bing Li Xue Za Zhi. 2007;36:282-3.

17. Vaideeswar P. Sclerosing hemangioma with lymph nodal metastases. Indian J Pathol Microbiol. 2009;52:392-4.
18. Suzuki H, Saitoh Y, Koh E, et al. Pulmonary sclerosing hemangioma with pleural dissemination: report of a case. Surg Today. 2011:41:258-61.

19. Bae YS, Ro JY, Shim HS, et al. Pulmonary sclerosing haemangioma with metastatic spread to stomach. Histopathology. 2012;60:1162-4.

20. Kita H, Shiraishi Y, Katsuragi N, et al. Pulmonary sclerosing hemangioma with lymph node metastasis. Kyobu Geka. 2013;66:1141-4.

21. Xu HM, Zhang G. A rare case of pulmonary sclerosing hemagioma with lymph node metastasis and review of the literature. Int I Clin Exp Pathol. 2015;8:8619-23.

22. Kim MK, Jang SJ, Kim YH, Kim SW. Bone metastasis in pulmonary sclerosing hemangioma. Korean J Intern Med. 2015;30:928-30.

23. Soo IX, Sittampalam K, Lim CH. Pulmonary sclerosing pneumocytoma with mediastinal lymph node metastasis. Asian Cardiovasc Thorac Ann. 2017;25:547-9.

24. Wang $X$, Zhang L, Wang $Y$, et al. Sclerosing pneumocytoma with metastasis to the mediastinal and regional lymph nodes. Indian J Pathol Microbiol. 2018;61:407-9

25. Wei S, Tian J, Song X, Chen Y. Recurrence of pulmonary sclerosing hemangioma. Thorac Cardiovasc Surg. 2008;56:120-2.

26. Iyoda A, Hiroshima K, Shiba M, et al. Clinicopathological analysis of pulmonary Sclerosing Hemangioma. Ann Thorac Surg. 2004;78:1928-31.

27. Liu W, Tian XY, Li Y, et al. Coexistence of pulmonary sclerosing hemangioma and primary adenocarcinoma in the same nodule of lung. Diagn Pathol. 2011;6:41.

28. Perl AK, Wilgenbus $P$, Dahl U, et al. A causal role for E-cadherin in the transition from adenoma to carcinoma. Nature. 1998;392:190-3.

29. Mon AM, Mackinnon AC Jr, Traktman P. Overexpression of the VRK1 kinase, which is associated with breast cancer, induces a mesenchymal to epithelial transition in mammary epithelial cells. PLoS One. 2018;13:e0203397.

30. Umbreit C, Erben P, Faber A, et al. Lapatinib-induced mesenchymal-epithelial transition in squamous cell carcinoma cells correlates with unexpected alteration of beta-catenin expression. Oncol Lett. 2016;11:2715-24.

31. Guo F, Parker Kerrigan BC, Yang D, et al. Post-transcriptional regulatory network of epithelial-to-mesenchymal and mesenchymal-to-epithelial transitions. J Hematol Oncol. 2014;7:19.

32. Hamilton G, Rath B. Mesenchymal-epithelial transition and circulating tumor cells in small cell lung Cancer. Adv Exp Med Biol. 2017;994:229-45.

\section{Publisher's Note}

Springer Nature remains neutral with regard to jurisdictional claims in published maps and institutional affiliations.

Ready to submit your research? Choose BMC and benefit from:

- fast, convenient online submission

- thorough peer review by experienced researchers in your field

- rapid publication on acceptance

- support for research data, including large and complex data types

- gold Open Access which fosters wider collaboration and increased citations

- maximum visibility for your research: over $100 \mathrm{M}$ website views per year

At $\mathrm{BMC}$, research is always in progress.

Learn more biomedcentral.com/submissions 